overall population. In order to reveal a lower, but still significant difference in the cystic fibrosis transmembrane regulator $\Delta \mathrm{F} 508$ allele prevalence, the number of patients should be increased dramatically. Hopefully, the worldwide existing large collections of DNA specimens from osteoporotic patients will provide an opportunity to enlighten the possible implication of a cystic fibrosis transmembrane regulator mutation in the development of osteoporosis.

\section{A. Treszl*, K. Németh", I. Kocsis*, B. Vásárhelyi ", G. Fekete ${ }^{\#}$, T. Tulassay ${ }^{*}$, and M. Szathmári ${ }^{+}$}

*First Dept of Paediatrics, "Second Dept of Paediatrics, "Research Laboratory for Paediatrics and Nephrology, Hungarian Academy of Sciences, and ${ }^{+}$First Dept of Internal Medicine, Semmelweis University, Budapest, Hungary.

This study was supported by grants OTKA D048351-T046086 and NKFP 1A/ 002/2004 from the Hungarian Government (Budapest).

\section{REFERENCES}

1 King SJ, Topliss DJ, Kotsimbos T, et al. Reduced bone density in cystic fibrosis: $\Delta \mathrm{F} 508$ mutation is an independent risk factor. Eur Respir J 2005; 25: 54-61.

2 Ujhelyi R, Treszl A, Vasarhelyi B, et al. Bone mineral density and bone acquisition in children and young adults with cystic fibrosis: a follow-up study. I Pediatr Gastroenterol Nutr 2004; 38: 401-406.

3 Elkin SL, Vedi S, Bord S, Garrahan NJ, Hodson ME, Compston JE. Histomorphometric analysis of bone biopsies from the iliac crest of adults with cystic fibrosis. Am J Respir Crit Care Med 2002; 166: 1470-1474.

4 Nemeth K, Fekete G, Kiss E, Varadi A, Holics K, Ujhelyi R. Analysis of five CFTR mutations in Hungarian cystic fibrosis patients. J Inherit Metab Dis 1996; 19: 378.

5 Fekete G, Varadi A, Pipiras E, et al. Detection of delta F508 mutation in cystic fibrosis. Orv Hetil 1992; 133: 2427-2430.

DOI: $10.1183 / 09031936.05 .00044605$

\title{
Tolerance to repeat exposure of inhaled endotoxin: an observation in healthy humans
}

\section{To the Editors:}

We read with interest the articles on endotoxin research in the May issue of the European Respiratory Journal. The editorial by BALS [1] aptly raised the yet unanswered questions concerning the timing (acute versus chronic) and doses of inhaled endotoxin relevant to health and disease, and the questions of whether the outcome of such exposure is always detrimental.

To this end, we wish to add our own preliminary observation of the possibility of tolerance to repeat exposure of inhaled lipopolysaccharide (LPS) in healthy nonatopic humans at 4 weeks. In a double-blind, crossover study, eight healthy human subjects were randomised to receiving either a single inhaled dose of $50 \mu \mathrm{g}$ salmeterol or placebo prior to being challenged with a $15-\mu \mathrm{g}$ dose of Escherichia coli serotype 026:B6 (Sigma, Poole, UK), in two visits separated by 4 weeks. Using 1 week prior as a baseline, sputum induced at the 6th $\mathrm{h}$ after LPS challenge showed no significant differences in the increase of total cell counts in the two treatment periods (mean difference $(95 \%$ confidence interval) salmeterol versus placebo: $10.6 \times 10^{6}$ cells $\cdot \mathrm{mL}^{-1}$ $(-9.71-30.9) ; \mathrm{p}=0.25)$ or neutrophils $\left(11.7 \times 10^{6} \mathrm{cells} \cdot \mathrm{mL}^{-1}\right.$ (-8.33-31.92); $\mathrm{p}=0.20$; unpublished data). The assertion that salmeterol does not protect against airway neutrophilic inflammation was subsequently supported in a more robust study, where subjects were randomised to receiving either daily salmeterol for 3 weeks or placebo, prior to inhaled LPS challenge, in a crossover study [2].
Retrospective power analysis of our results first alerted us to the possibility of intrinsic biological phenomena in a study design of sequential inhaled LPS challenges. Data were then re-analysed with the purpose of looking into the reproducibility of sputum neutrophilia between the two inhaled challenges, treating the effects of the single-dose salmeterol as no more than placebo [2]. Our findings showed that following the first LPS challenge, the mean total sputum cell counts increased by $31.23 \times 10^{6}$ cells $\cdot \mathrm{mL}^{-1}(95 \%$ CI: $13.27-$ 49.20 ) and the mean sputum neutrophil counts rose by $30.3 \times 10^{6}$ cells $\cdot \mathrm{mL}^{-1}(12.59-48.11)$. However, following the second LPS challenge, the mean total sputum cell counts only increased by $11.3 \times 10^{6}$ cells $\cdot \mathrm{mL}^{-1}(2.14-24.89)$ and mean sputum neutrophil counts by $10.9 \times 10^{6}$ cells $\cdot \mathrm{mL}^{-1}(1.02-22.9)$. The difference between the means was statistically significant ( $\mathrm{p}=0.01$; mean difference: $19.8 \times 10^{6}$ cells $\cdot \mathrm{mL}^{-1}(6.16-33.56)$ for total sputum cell counts; $19.4 \times 10^{6}$ cells $\cdot \mathrm{mL}^{-1}(4.73-34.08)$ for sputum neutrophil counts; fig. 1).

Using such a human experimental model of airway neutrophilia to understand the inhaled effects of endotoxin [3], and to examine for potential anti-inflammatory properties of therapeutic agents [2] appears to be a validated approach. Michel et al. [3] employed a model of weekly inhaled challenges of incremental LPS doses $(0.5 \mu \mathrm{g}, 5 \mu \mathrm{g}$ and $50 \mu \mathrm{g})$ to provide evidence for dose responsiveness of LPS in airway inflammation and systemic effects in healthy human subjects. WALLIN et al. [2] tested for possible antiinflammatory effect of salmeterol versus placebo, via findings from bronchoscopy, based on a study design of inhaling $50 \mu \mathrm{g}$ 


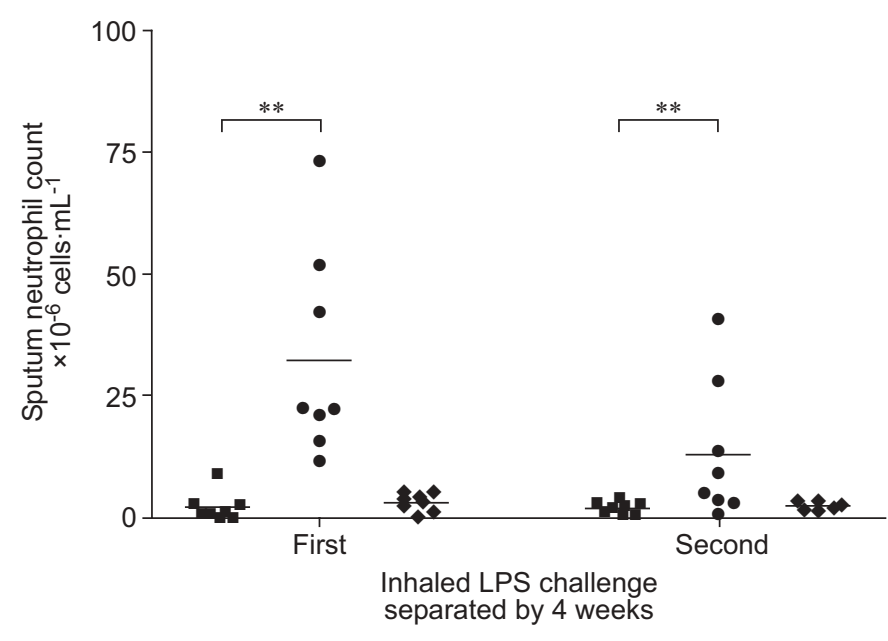

FIGURE 1. Comparison of sputum neutrophilia post-inhaled lipopolysaccharide (LPS; 6 th $h$ ) between two inhaled LPS challenges separated by 4 weeks. baseline; $\bullet: 6 \mathrm{~h}$ post-inhaled LPD; $\bullet 1$ week post-inhaled LPS. **: denotes $p=0.01$ between the mean differences.

LPS on two occasions separated by $\geqslant 3$ weeks. However, none of these studies had observed tolerance towards subsequent LPS challenge(s) in their healthy human subjects at doses of LPS described that were higher than ours. It is possible that tolerance in healthy nonatopic human subjects only occurs in exposure to lower doses of inhaled endoxin. In fact, existing literature indicates that exposure of 30-40 $\mu \mathrm{g}$ inhaled LPS is probably the clinical threshold to induce symptoms and lung function changes for healthy subjects [4].

More research is required to validate our preliminary observation.

\section{L.C. Loh}

Dept of Medicine, Clinical School, International Medical University, Jalan Rasah, Malaysia.

\section{REFERENCES}

1 Bals R. Lipopolysaccharide and the lung: a story of love and hate. Eur Respir J 2005; 25: 776-777.

2 Wallin A, Pourazar J, Sandstrom T. LPS-induced bronchoalveolar neutrophilia; effects of salmeterol treatment. Respir Med 2004; 98: 1087-1092.
3 Michel O, Nagy AM, Schroeven M, et al. Dose-response relationship to inhaled endotoxin in normal subjects. Am J Respir Crit Care Med 1997; 156: 1157-1164.

4 Thorn J. The inflammatory response in humans after inhalation of bacterial endotoxin: a review. Inflamm Res 2001; 50: 254-261.

DOI: 10.1183/09031936.05.00058405

From the author:

The study that L.C. Loh describes in his letter above adds another interesting aspect that is critical for the response to inhaled endotoxin.

Lipopolysaccharide tolerance is a well-known feature of several host defence cells, although the mechanisms involved are not entirely clear [1]. Tolerance has also been shown to be associated with various cellular processes, such as decreased activity of $\mathrm{Gi}$ proteins, protein kinase $C$, mitogen-activated protein kinase, activator protein-1 and nuclear factor- $\mathrm{kB}(\mathrm{NF}-\kappa \mathrm{B})$. Inhibitory molecules such as IRAK-M, suppressor of cytokine-signaling-1 and inhibitor- $\kappa \mathrm{B}$ are found activated. At the nuclear level, the NF- $\kappa$ B subunit p50 homodimer expression and peroxisomeproliferator-activated receptors $-\gamma$ are increased. There is evidence from rodent studies that this phenomenon is also relevant for pulmonary innate immunity [2].

The preliminary results described in this letter support this view and it is likely that this mechanism is of biological relevance, because the lung is constantly exposed to small amounts of lipopolysaccharide. The pulmonary exposure with endotoxin probably has many consequences. At this time it is uncertain where lipopolysaccharide tolerance is functionally located in this scenario.

\section{R. Bals}

Hospital of the University of Marburg, Marburg, Germany.

\section{REFERENCES}

1 Fan H, Cook JA. Molecular mechanisms of endotoxin tolerance. J Endotoxin Res 2004; 10: 71-84.

2 Shimada M, Tsukada $\mathrm{H}$, Ishizuka $\mathrm{O}$, et al. Lipopolysaccharide tolerance in relation to intrabronchial influx of neutrophils in the rat. Lung 2000; 178: 235-248.

DOI: 10.1183/09031936.05.00062205

\section{Pre-analytical conditions for the assessment of circulating MMP-9 and TIMP-1: consideration of pitfalls}

\section{To the Editors:}

We read with interest the recent article of HigAshimoto et al. [1], which reported an increased activity of tissue inhibitor of metalloproteinase (TIMP)-1 in patients with chronic obstructive pulmonary disease (COPD) and asthma. In contrast, the molar ratio between matrix metalloproteinase (MMP)-9 and TIMP-1 was significantly lower in COPD patients than in normal subjects. 